\title{
Increased ENT2 Expression and Its Association with Altered Purine Metabolism in Different Stages of Colorectal Cancer Cell Lines
}

\section{Safaa M. Naes}

Universiti Teknologi MARA

Sharaniza Ab-Rahim

Universiti Teknologi MARA

Musalmah Mazlan

Universiti Teknologi MARA

Nurul Azmir Amir Hashim

Universiti Teknologi MARA

Amirah Abdul Rahman ( $\nabla$ amirahar@uitm.edu.my )

Universiti Teknologi MARA https://orcid.org/0000-0002-3566-1787

\section{Research Article}

Keywords: Colorectal Cancer, Hypoxanthine, Hypoxanthine Phosphoribosyl Transferase, Xanthine Oxidase

Posted Date: April 6th, 2022

DOl: https://doi.org/10.21203/rs.3.rs-1199487/v2

License: (c) (1) This work is licensed under a Creative Commons Attribution 4.0 International License. Read Full License 


\section{Abstract}

Colorectal cancer (CRC) is one of the most prevalent malignant cancers worldwide. Although the purine metabolism pathway is known to be vital for cancer cells survival mechanism, not much is known on equilibrative nucleoside transporter 2 (ENT2) role in CRC development and its association with purine metabolites. Hence this study is aimed to determine the level of hypoxanthine phosphoribosyl transferase (HPRT), hypoxanthine, uric acid (UA), and the activity of xanthine oxidase (XO) and relate the findings with the ENT2 expression level in different CRC stages. Normal colon cell line; CCD-841CoN and a panel of human CRC cell lines; SW480, HCT15 and HCT116, representing different CRC stages; Dukes' B, C, and D respectively, have been used to measure HPRT, hypoxanthine/xanthine, UA levels and the activity of XO. The level of ENT2 expression was also performed by qRT-PCR. The levels of HPRT, hypoxanthine were significantly higher $(P<0.05)$, while XO and UA were lower $(P<0.05)$ in all CRC stages as compared to the normal colon cells. Furthermore, ENT2 expression was found to be increased in all CRC stages. Despite having the highest level of HPRT and hypoxanthine, ENT2 level is lower in Dukes' D when compared to Dukes' B and C. The rate of salvage pathway is increased in CRC development as indicated by the elevated levels of HPRT and hypoxanthine in different CRC stages. Increased ENT2 expression implies its importance in assisting hypoxanthine uptake which is vital to increase DNA synthesis via hypoxanthine recycling. Thus, ENT2 may be a potential marker in CRC therapeutic development.

\section{Introduction}

Colorectal cancer (CRC) ranks as the third most common malignant cancer in terms of incidence and the second in terms of mortality worldwide [1]. In 2018, around $10 \%$ of new cases and death of cancers have been recorded due to CRC [2]. Dukes' staging system classified CRC into four groups known as Dukes' A (Stage I), Dukes' B (Stage II), Dukes' C (Stage III), and Dukes' D (Stage IV) [3]. CRC develops through a multistep process including a serial of morphological, histological, and genetic alterations that accumulate over time [4]. The metabolic reprogramming of cancer cells allows them to maintain the redox homeostasis, while increasing the ATP production to meet the high energy demand [5]. Recent interest has shifted to purine metabolism, where the alteration of this pathway including the modification of the enzymes activities have been correlated with disease progression [6].

Purine metabolites serve as the building blocks for DNA and RNA as well as supplying the cells with essential energy and cofactors to enhance cell survival and proliferation [7]. Purine nucleosides, such as adenosine, guanine, and inosine, function as signalling molecules [8] and act as precursors to ATP and GTP nucleotides during DNA and RNA synthesis [7]. It was demonstrated that insufficient supply of nucleotides during DNA replication can lead to slower replication process, which will eventually trigger DNA damage and genomic instability [9]. Previous studies have indicated that purine anti-metabolites treatment against cancer cells blocked the DNA synthesis and subsequently inhibited cancer cell growth $[10 ; 11]$. Purine levels are maintained by a harmonic action of both de novo and salvage biosynthetic pathways. During normal physiological conditions, degraded bases will be recycled via salvage pathway to sustain the cellular purine pool [12]. In addition, the existing bases in the extracellular matrix can be 
transported into the cells to generate the nucleotides [7]. On the contrary, in cancer cells environment, high levels of purine will be required, thus necessity is met by upregulating the de novo biosynthetic pathway [7].

Purine nucleosides are hydrophilic and, therefore, demand special membrane transport proteins, known as nucleoside transporters (NTs) translocate nucleosides across plasma membranes. NTs are classified into two families depending on the transport mechanisms: $\mathrm{Na}+$-dependent concentrative transporters (CNTs, encoded by SLC28 gene) and equilibrative nucleoside transporters (ENTs, encoded by SLC29 gene) [13]. ENTs are facilitating transporter proteins driven solely by the concentration gradient of nucleoside permeants in/out of the cells [14]. ENT2, the second member of ENTs family, has the ability to transport the nucleoside and a wide range of purine and pyrimidine nucleobases with a unique function in transporting hypoxanthine [15]. Hypoxanthine serves as one of the sources for purines in salvage pathway for nucleotide synthesis [16]. Any interruption in the ENT2 expression and/or its activity could be deleterious to the cells whereby it was suggested that intracellular accumulation of the reactive oxygen species (ROS), a by-product of purine catabolism pathway, may disrupt the redox balance and ultimately kill the cancer cells [17]. Besides that, ENT2 and other NTs, play a crucial role in the disposition of the nucleoside analogues of some anticancer, such as 5 -fluorouracil (5FU), which is widely used as a chemotherapeutic drug to treat gastrointestinal cancer, particularly colorectal cancer [18] and antiviral drugs, for example, remdesivir which is one of the treatments for COVID-19 patients [19].

In this study, we aimed to evaluate the changes in purine salvage and catabolism pathways by determining the level of hypoxanthine phosphoribosyl transferase (HPRT), hypoxanthine/ xanthine, uric acid (UA), and the activity of xanthine oxidase $(\mathrm{XO})$ and relate the findings with the ENT2 expression level in different CRC stages.

\section{Material And Methods}

\section{Cell culture}

Cell lines were purchased from American Type Culture Collection (ATCC, Rockville, MD, USA). In this study, we used a panel of human colorectal cancer (CRC) cell lines representing different CRC stages and normal colon epithelial cell line. CCD-481CoN cell line was used as a normal colon epithelial cell line, and SW480 (Dukes' B), HCT15 (Dukes' C) and HCT116 (Dukes' D) cell lines were used as CRC cell lines. CRC stages were classified according to the tumour staging which follows Dukes' classification criteria. All cells were cultured in Dulbecco's Modified Eagle Medium (DMEM, high glucose, Nacalai Tesque, Japan) supplemented with $10 \%$ fetal bovine serum (FBS, Gibco, USA) and $1 \%$ penicillin-streptomycin (SigmaAldrich, USA). Cells were incubated at $37^{\circ} \mathrm{C}$ in a humidified incubator, BINDER (Tuttlingen, Germany), with $5 \% \mathrm{CO}_{2}$.

\section{Cell lysate preparation}


Briefly, after the cells were quantified, cells were resuspended in the assay buffer. The cells were then homogenized using the homogenizer Ultrasonic Vibracell (Sonics and Materials, Connecticut, USA) by

pulsing for $5 \mathrm{sec}$ and resting for $25 \mathrm{sec}$ in 10 cycles. The tube containing cells lysate was homogenized in ice to reduce the heat produced by ultrasonic. Tubes containing cell lysate and debris were centrifuged at $14000 \mathrm{rpm}, 4^{\circ} \mathrm{C}$ for 10 minutes. The supernatants were transferred to new tubes and kept at $-20^{\circ} \mathrm{C}$ until further use.

\section{HPRT ELISA assay}

HPRT level was measured using an ELISA sandwich technique for HPRT (Cloud-Clone Corp, USA, Cat. No. SEA717Hu) according to the manufacturer's instructions. Cells were lysed as described above. Detection assay is based on the horseradish peroxidase (HRP) colorimetric reaction by adding tetramethylbenzidine (TMB) substrate. The absorbance was measured immediately at $450 \mathrm{~nm}$ using microplate reader (BMG Labtech, Germany).

\section{Xanthine oxidase $(\mathrm{XO})$ assay}

The $\mathrm{XO}$ activity was quantified spectrophotometrically using the xanthine oxidase activity colorimetric assay kit (Biovision, USA, Cat. No. K710). The assay is based on XO in the sample oxidizing xanthine to hydrogen peroxide $\left(\mathrm{H}_{2} \mathrm{O}_{2}\right)$, which reacts stoichiometrically with OxiRed Probe to generate colour at an optical density of $570 \mathrm{~nm}$. Briefly, $44 \mu$ lassay buffer, $2 \mu$ l enzyme Mix, $2 \mu$ l substrate mix and $2 \mu$ OxiRed probe were mixed and added into the designated wells on the plate. The reactions were initiated by adding $50 \mu \mathrm{L}$ of prepared $2 \mu \mathrm{l}$ standard or cell lysate into each well. The absorbance measurements (A1 and A2) had been taken after incubation in the dark at room temperature by using microplate reader (BMG Labtech, Germany) at wavelength $570 \mathrm{~nm}$. The standard curve was plotted by several dilutions of $\mathrm{H}_{2} \mathrm{O}_{2}$ standard and the volume was adjusted to $50 \mu \mathrm{l} /$ well by $\mathrm{dH}_{2} \mathrm{O}$. The $\mathrm{XO}$ activity of the samples was calculated using the equation as shown below:

$X O$ Activity $=\frac{(B X \text { Dilution Factor })}{(T 2-T 1) X V}=m U / m L$

$\mathrm{B}=$ the amount of $\mathrm{H}_{2} \mathrm{O}_{2}$ generated by $\mathrm{XO}$ from standard curve (nmol)

$\mathrm{T} 1=$ the time of the first reading $(\mathrm{A} 1)(\mathrm{min})$

$\mathrm{T} 2=$ the time of the second reading $(\mathrm{A} 2)(\mathrm{min})$

$V=$ pre-treated sample volume added into the reaction well $(\mathrm{ml})$

\section{Hypoxanthine/xanthine assay}

Hypoxanthine/ xanthine level in all cell lines was detected using a xanthine/hypoxanthine colorimetric assay kit (Biovision, USA-Cat. No. K685). According to the manufacturer's instructions, cells $(1 \times 106)$ 
were incubated on ice with $100 \mu \mathrm{l}$ ice-cold xanthine assay buffer for $10 \mathrm{~min}$, after centrifuging at 12,000 $\mathrm{rpm}$ for $5 \mathrm{~min}$, the supernatant was collected and incubated with the Reaction Mix for $30 \mathrm{~min}$ at room temperature. A standard curve was plotted by several dilutions of xanthine standard and the volume was adjusted to $50 \mu \mathrm{l} /$ well by xanthine assay buffer. The absorbance was measured at the wavelength of $570 \mathrm{~nm}$.

\section{Uric acid (UA) assay}

Uric acid quantification was performed by using uric acid colorimetric assay Kit, (BioVision, USA, Cat. No. K608) according to manufacturer's instructions. Briefly, $46 \mu \mathrm{l}$ UA assay buffer, $2 \mu \mathrm{l}$ UA enzyme Mix and 2 $\mu \mathrm{l}$ UA probe were mixed and added into the designated wells on the plate. The reactions were initiated by adding $50 \mu \mathrm{l}$ of prepared UA standard or cell lysate into each well. The plates were incubated for 30 minutes at $37^{\circ} \mathrm{C}$ and protected from light. A standard curve was plotted by several dilutions of UA standard and the volume was adjusted to $50 \mu \mathrm{l} /$ well by UA assay buffer. The absorbance was measured at wavelength $570 \mathrm{~nm}$.

\section{RNA isolation and CDNA synthesis}

Total RNA from all cells lines was extracted using nucleospin RNA extraction kit (Macherey-Nagel, Germany, Cat. No. 740955) according to the manufacturer's instructions. Total RNA concentration and the absorbance ratio (A230/208 and $260 / 280 \mathrm{~nm}$ ) of the RNA initial quality were measured by using SpectraMax ${ }^{\circledR}$ QuickDrop ${ }^{\text {TM }}$ UV-Vis spectrophotometer (Molecular Devices, USA). RNA integrity was assessed by gel electrophoresis assay. According to the manufacturer's instructions, $200 \mathrm{ng}$ of the total RNA was used for reverse transcription using SensiFAST ${ }^{T M}$ CDNA Synthesis kit (Bioline, UK, Cat. No. BIO65053).

\section{Quantitative real-time PCR (qRT-PCR)}

qRT-PCR was performed using a CFX96 machine (BioRad, Japan). The reactions were carried out in triplicate using intercalating dye SensiFAST ${ }^{\mathrm{TM}}$ SYBR ${ }^{\circledR}$ \& Fluorescein kit (Bioline, UK, Cat. No. BI096005) following the manufacturer's instructions. The sequence of oligonucleotide primers that were used for qRT-PCR amplifications was listed in Table 1. Each reaction was performed to a final volume of $10 \mu \mathrm{L}$, and the concentration of primers was at $400 \mathrm{nM}$. The Thermocycler program was adjusted with an initial start cycle at $95^{\circ} \mathrm{C}$ for $2 \mathrm{~min}$, followed by 39 cycles at $95^{\circ} \mathrm{C}$ for $5 \mathrm{sec}$ and $60^{\circ} \mathrm{C}$ for $30 \mathrm{sec}$. To confirm product specificity, melting curve analysis was performed after each amplification. Two independent reference genes, GAPDH and HPRT1 were used for normalization. The human CRC cell lines ENT2 expression fold change relative to normal colon cell line was determined by using the $2^{-\triangle \Delta C T}$ method.

Table 1: Primer sequences used for qPCR 


\begin{tabular}{|lll|}
\hline Gene & Forward & Reverse \\
\hline ENT2 & 5'-CCACTCTCTCACCGAAGCCTAA- 3' & 5'-GCAGGAAGAACAGCACCAACA-3' \\
\hline GAPDH & 5'-GCATCCTGGGCTACACTGAG-3' & 5'-TCCTCTTGTGCTCTTGCTGG-3' \\
\hline HPRT1 & 5'-GAGTCCTATTGACATCGCCAGT-3' & 5'-TCCGCCCAAAGGGAACTGAT-3' \\
\hline
\end{tabular}

\section{Statistical Analysis}

All data were statistically analyzed by utilizing IBM SPSS Statistical Software Version 27 (International Business Machines Corp, New York). The results were expressed as means \pm SD. The significant difference between the two groups was assessed using the Student's $t$ test, and the differences between multiple groups were assessed by two-way analysis of variance (ANOVA). Statistical evaluation of ENT2 gene expression was performed using CFX96 software followed by one-way ANOVA. $P<0.05$ was considered statistically significant.

\section{Results}

\section{Enzymes levels}

HPRT is one of the salvage pathway enzymes involved in regulating cell proliferation and cell cycle progression [20]. HPRT levels were measured in normal colon cells and CRC cells by binding of HPRT to antibody in ELISA assay. The results showed that HPRT levels were significantly increased $(p \leq 0.05)$ in SW480, HCT15 and HCT116 cell lines compared to normal colon cells. HPRT levels in Dukes' B, and D were significantly higher than Dukes' $\mathrm{C}$ stages of CRC (Fig. 1a). The data of XO enzymatic activity in all CRC cell lines were significantly lower $(p \leq 0.05)$ than normal colon cells. XO activity was decreased in Dukes' B, C, and D stages of CRC (Fig. 1b).

\section{Metabolites levels}

The concentrations of hypoxanthine/xanthine in CRC cell lines were significantly higher $(p \leq 0.05)$ as compared to normal colon cells. Hypoxanthine/ xanthine ranging were from 2.86 to $5.08 \mu \mathrm{M}$ in CRC cell lines compared to $0.92 \mu \mathrm{M}$ in normal colon cells. We found that hypoxanthine/ xanthine levels are increasing in advanced CRC stages with 3.1, 4.2, and 5.5 fold higher in Dukes' B, C, and D stages of CRC, respectively. Hypoxanthine/xanthine level was significantly higher in Dukes' D in comparison with Dukes' B (Fig. 2a). UA level was significantly lower $(p \leq 0.05)$ in HCT15 and HT116 cell lines as compared to normal colon cells. Moreover, UA level was significantly lower $(p \leq 0.05)$ in Dukes' $C$ and $D$ compared to Dukes' B stages of CRC (Fig. 2b).

\section{ENT2 gene expression}


ENT2 was significantly upregulated in all CRC cell lines (SW480, HCT15 and HCT116) in comparison with normal colon cells $(P<0.05)$ (Fig. 3). We found that the ENT2 expression level was 186, 471, and 123folds higher in Dukes' B, C, and D stages of CRC, respectively. ENT2 expression level was the highest in Dukes' C stage. Interestingly, ENT2 expression level was lower in Dukes' D stage as compared to the Dukes' B stage of the CRC cells.

\section{Discussion}

Purine metabolism was observed to be one of the most affected pathways not only in CRC [21;22] but also in other cancers, for instance, breast cancer [23] and urothelial carcinoma [24]. In addition to the alteration of the enzymes pattern in purine metabolism [25], it has been reported that impaired purine metabolism dysfunction was associated with cancer progression. For example, several types of cancers expressed a high level of HPRT, the key enzyme of the salvage pathway, thus promoting the metabolic flux in order to produce purine mononucleotides as the precursors for nucleic acid synthesis [26]. In this study, the levels of HPRT and hypoxanthine/ xanthine were significantly increased in CRC stages, notably in advanced stages, whereas XO and UA levels were significantly decreased in CRC stages as compared to normal colon cells.

HPRT was reported to be upregulated in a number of solid cancers, like breast, lung, colon and prostate cancers [27]. Supporting our results, it was demonstrated that HPRT activity was significantly higher in colorectal cancer [28] and breast cancer [29], with significant progressive increase in HPRT activity with clinical parameters of human colon carcinoma diffusion [30]. Under physiological conditions, the concentration of hypoxanthine is very low [31]. However, it was reported that in several metabolomics studies, hypoxanthine level was elevated in lymphoblastic leukemia, lung cancer, and prostate cancer [32]. Similar to our findings, hypoxanthine level was found to be elevated in CRC tissues along with decreasing in UA level [33]. Therefore, our data suggested the increased level of hypoxanthine is correlated with CRC progression. Consistent with our findings, several studies reported that XO activity was decreased in a number of cancers, such as colon cancer [34], kidney and bladder [35]. In addition, low XO expression was correlated with more aggressive cancers [36], indicating that XO plays an important role in cancer progression and may become a risk factor [37]. The decrease in $\mathrm{XO}$ activity might provide an advantage to the cancer cells by reducing the generation of ROS, which may induce the apoptosis pathway and cell death. Uric acid was observed to be elevated in advanced stages of rectal cancer [38] and head and neck carcinoma [39]. Contrary, our data showed that UA level had been decreased significantly among the CRC stages in comparison with the normal colon cells. This decrease was also correlated with the low activity of XO in all CRC stages in this study. The controversy over the role of uric acid in tumorigenesis has not been resolved yet. Several studies have correlated the increase of serum UA level (hyperuricemia) with increased cancer risk due to its pro-inflammatory properties [40]. In contrast, other studies suggested that UA plays an important role as a potent antioxidant [26]. It was suggested that increased level of UA may have a protective role in tumour defence; first, by protecting the cells against free-radical oxidative damage when it acts as antioxidants and second, by stimulating the 
immune system [41]. Therefore, some studies reported that elevated level of UA was correlated with increased survival time of CRC patients [42].

On the other hand, we found that ENT2 expression was significantly higher in all CRC stages as compared to normal colon cells. Interestingly, Dukes' D (stage IV) expressed a lower level of ENT2 compared to Dukes' B and C (stage II \& III). Similarly, a high level of the ENT2 expression was correlated with advanced stages of several cancers including mantle cell lymphoma, ovarian carcinoma and hepatocellular carcinoma [43]. In this study, the down-regulation of ENT2 in Dukes' D compared to Dukes' $B$ and $C$ was correlated by increasing the level of hypoxanthine, an endogenous substrate of ENT2, and HPRT, a salvage purine metabolism enzyme [26] (Fig. 4). During salvage purine metabolism, hypoxanthine can be either recycled to inosine monophosphate (IMP) by HPRT or synthesized by deamination of adenosine by adenosine deaminase (ADA) to produce inosine; inosine will be converted to hypoxanthine by purine nucleoside phosphorylase (PNP) [28]. Later, during the purine catabolism pathway, hypoxanthine will be converted to xanthine then to uric acid by xanthine oxidase. Reactive oxygen species (ROS) will be produced as a by-product of the catabolism pathway [37]. The increasing level of intracellular ROS is postulated to induce apoptosis and cancer cell death. Hence in order to avoid the detrimental effects of ROS, cancer cells may modify the regulation of metabolic pathways, and this adaptation allows them to adapt and thrive in a tough environment [33]. As a result, some of the hypoxanthine will be transported out of the cells by ENTs, particularly ENT2 [44].

These findings might explain the contradictory findings between the studies that observed high hypoxanthine level in the serum of CRC patients [6] and the studies that observed a reduction in the hypoxanthine level in colorectal cancer [45], particularly in advanced stages [22]. The remaining intracellular hypoxanthine will be recycled by HPRT to support the demanded production of nucleotides required to maintain the rapid cell proliferation in cancer growth [26].

Taken together, our findings revealed that the high level of HPRT and hypoxanthine indicated an increase in the rate of salvage pathway to meet the demand of rapid cell proliferation by generating new nucleotides for DNA synthesis via hypoxanthine recycling. Furthermore, the catabolism pathway was decreased as evidenced by decreased XO and UA levels to maintain the anti-oxidant balance and avoid ROS toxicity and subsequently apoptosis. As a result, the alteration of enzymes and metabolites levels involved in the purine salvage/ catabolism pathway might have diagnostic and prognostic importance during CRC progression. On the other hand, ENT2 may play a critical role in regulating the transportation of these metabolites in order to support cancer cell survival and proliferation.

In conclusion, $\mathrm{CRC}$ cells may utilize hypoxanthine via the salvage pathway in order to meet the energy demand of rapid cell proliferation. Furthermore, the detrimental effect of accumulating ROS resulting from the catabolic metabolism may be avoided as evident by decreasing XO enzyme and UA production. Interestingly, the upregulation of ENT2 may also indicate that any excessive hypoxanthine might be transported out of the cells to maintain the intracellular redox balance. Further investigations are needed 
to elucidate the level of ROS and ENT2 role and function in colorectal carcinogenesis. ENT2 silencing may be a potential therapeutic target to improve the effectiveness of colorectal cancer treatment.

\section{Declarations}

\section{Funding}

This study was supported by Ministry of Higher Education Government of Malaysia under the Long-Term Research Grant, No: LRGS/2014/UKM-UiTM/K/03, and the Fundamental Research Grant Scheme, No: FRGS/1/2019/SKK08/UITM/02/11; and funded by the National Cancer Council (Majlis Kanser Nasional (MAKNA)), No: 100-IRMI/16/6/2 (011/2019).

\section{Conflict of interest}

The authors declare that they have no confict of interest.

\section{Author contributions}

Conceptualization, methodology and funding acquisition: MM and AAR. Lab Experiment and Analysis: SMN and NAAH. Writing- Original Draft: SMN. Review, Editing, and Supervision: SAR, AAR and MM.

\section{Data availability}

The data used to support the findings of this study are available from the corresponding author upon reasonable request.

\section{Consent to participate and publish}

All authors reviewed and approved the final version for publication.

\section{Ethical approval}

This article does not contain any studies with human participants performed by any of the authors.

\section{Acknowledgements}

Authors are thankful to Malaysia's ministry of higher education and the National Cancer Council (Majlis Kanser Nasional (MAKNA)) for their grant support.

\section{References}

1. Wong MC, Huang J, Lok V, Wang J, Fung F, et al. Differences in incidence and mortality trends of colorectal cancer worldwide based on sex, age, and anatomic location. Clin Gastroenterol Hepatol. 2021;19:955-66. e61. 
2. Xie Y-H, Chen Y-X, Fang J-Y. Comprehensive review of targeted therapy for colorectal cancer. Signal Transduct Target therapy. 2020;5:1-30.

3. Peravali R, Hall N. Colorectal cancer: features and investigation. Medicine. 2015;43:299-302.

4. Simon K. Colorectal cancer development and advances in screening. Clin Interv Aging. 2016;11:967.

5. Martinez-Outschoorn UE, Peiris-Pagés M, Pestell RG, Sotgia F, Lisanti MP. Cancer metabolism: a therapeutic perspective. Nat reviews Clin Oncol. 2017;14:11-31.

6. Hashim NAA, Ab-Rahim S, Ngah WZW, Nathan S, Ab Mutalib NS, et al. Global metabolomics profiling of colorectal cancer in Malaysian patients. Biolmpacts: BI. 2021;11:33.

7. Pedley AM, Benkovic SJ. A new view into the regulation of purine metabolism: the purinosome. Trends Biochem Sci. 2017;42:141-54.

8. Di Virgilio F, Adinolfi E. Extracellular purines, purinergic receptors and tumor growth. Oncogene. 2017;36:293-303.

9. Bester AC, Roniger M, Oren YS, Im MM, Sarni D, et al. Nucleotide deficiency promotes genomic instability in early stages of cancer development. Cell. 2011;145:435-46.

10. Yin J, Ren W, Huang X, Deng J, Li T, Yin Y. Potential mechanisms connecting purine metabolism and cancer therapy. Front Immunol. 2018;9:1697.

11. Rosenthal E, Chung T, Parker W, Allan P, Clemons L, et al. Phase I dose-escalating trial of Escherichia coli purine nucleoside phosphorylase and fludarabine gene therapy for advanced solid tumors. Ann Oncol. 2015;26:1481-7.

12. Yamaoka $\mathrm{T}$, Kondo $\mathrm{M}$, Honda $\mathrm{S}$, Iwahana $\mathrm{H}$, Moritani $\mathrm{M}$, et al. Amidophosphoribosyltransferase limits the rate of cell growth-linked de novo purine biosynthesis in the presence of constant capacity of salvage purine biosynthesis. J Biol Chem. 1997;272:17719-25.

13. dos Santos-Rodrigues A, Grañé-Boladeras N, Bicket A, Coe IR. Nucleoside transporters in the purinome. Neurochem Int. 2014;73:229-37. doi:10.1016/j.neuint.2014.03.014.

14. Cass CE, Young JD, Baldwin SA, Cabrita MA, Graham KA, et al (2002) Nucleoside transporters of mammalian cells. Membrane transporters as drug targets:313 - 52.

15. Naes SM, Ab-Rahim S, Mazlan M, Abdul Rahman A. (2020) Equilibrative Nucleoside Transporter 2: Properties and Physiological Roles. BioMed Research International 2020.

16. Young JD, Yao SY, Baldwin JM, Cass CE, Baldwin SA. The human concentrative and equilibrative nucleoside transporter families, SLC28 and SLC29. Mol. Aspects Med. 2013;34:529-47. doi:10.1016/j.mam.2012.05.007.

17. Tang PC, Yang C, Li RW-S, Lee SM-Y, Hoi MP-m, et al. Inhibition of human equilibrative nucleoside transporters by 4-((4-(2-fluorophenyl) piperazin-1-yl) methyl)-6-imino-N-(naphthalen-2-yl)-1, 3, 5triazin-2-amine. Eur J Pharmacol. 2016;791:544-51. doi:10.1016/j.ejphar.2016.07.002.

18. Phua LC, Mal M, Koh PK, Cheah PY, Chan ECY, Ho HK. Investigating the role of nucleoside transporters in the resistance of colorectal cancer to 5-fluorouracil therapy. Cancer Chemother Pharmacol. 2013;71:817-23. doi:10.1007/s00280-012-2054-0. 
19. Al-Tawfiq JA, Al-Homoud AH, Memish ZA. Remdesivir as a possible therapeutic option for the COVID19. Travel Med. Infect Dis. 2020;34:101615.

20. Townsend MH, Felsted AM, Burrup W, Robison RA, O'Neill KL. Examination of Hypoxanthine Guanine Phosphoribosyltransferase as a biomarker for colorectal cancer patients. Mol Cell Oncol. 2018;5:e1481810.

21. Brown DG, Rao S, Weir TL, O'Malia J, Bazan M, et al. Metabolomics and metabolic pathway networks from human colorectal cancers, adjacent mucosa, and stool. Cancer \& metabolism. 2016;4:11.

22. Long Y, Sanchez-Espiridion B, Lin M, White L, Mishra L, et al. Global and targeted serum metabolic profiling of colorectal cancer progression. Cancer. 2017;123:4066-74.

23. Luo X, Yu H, Song Y, Sun T. Integration of metabolomic and transcriptomic data reveals metabolic pathway alteration in breast cancer and impact of related signature on survival. J Cell Physiol. 2019;234:13021-31.

24. Sahu D, Lotan Y, Wittmann B, Neri B, Hansel DE. Metabolomics analysis reveals distinct profiles of nonmuscle-invasive and muscle-invasive bladder cancer. Cancer Med. 2017;6:2106-20.

25. Zhu J, Djukovic D, Deng L, Gu H, Himmati F, et al. Colorectal cancer detection using targeted serum metabolic profiling. J Proteome Res. 2014;13:4120-30.

26. Garcia-Gil M, Camici M, Allegrini S, Pesi R, Petrotto E, Tozzi M. Emerging role of purine metabolizing enzymes in brain function and tumors. Int J Mol Sci. 2018;19:3598.

27. Townsend MH, Felsted AM, Ence ZE, Piccolo SR, Robison RA, O’Neill K. Elevated expression of hypoxanthine guanine phosphoribosyltransferase within malignant tissue. Cancer Clin Oncol. 2017;6:19-34.

28. Sedano J, Ramos MI, Choudhari E, Harrison RL, Subramani A R, et al. Hypoxanthine phosphoribosyl transferase 1 is upregulated, predicts clinical outcome and controls gene expression in breast cancer. Cancers (Basel). 2020;12:1522.

29. Camici M, Tozzi MG, Allegrini S, Del Corso A, Sanfilippo O, et al. Purine salvage enzyme activities in normal and neoplastic human tissues. Cancer Biochem Biophys. 1990;11:201-9.

30. Sanfilippo O, Camici M, Tozzi MG, Turriani M, Faranda A, et al. Relationship between the levels of purine salvage pathway enzymes and clinical/biological aggressiveness of human colon carcinoma. Cancer Biochem Biophys. 1994;14:57-66.

31. Nemkov T, Sun K, Reisz JA, Song A, Yoshida T, et al. Hypoxia modulates the purine salvage pathway and decreases red blood cell and supernatant levels of hypoxanthine during refrigerated storage. Haematologica. 2018;103:361-72.

32. Kami K, Fujimori T, Sato H, Sato M, Yamamoto H, et al. Metabolomic profiling of lung and prostate tumor tissues by capillary electrophoresis time-of-flight mass spectrometry. Metabolomics. 2013;9:444-53.

33. Ong ES, Zou L, Li S, Cheah PY, Eu KW. Metabolic profiling in colorectal cancer reveals signature metabolic shifts during tumorigenesis. Mol. Cell. Proteomics; 2010. 
34. Durak I, Cetin R, Devrim E, Ergüder IB. Effects of black grape extract on activities of DNA turn-over enzymes in cancerous and non cancerous human colon tissues. Life Sci. 2005;76:2995-3000.

35. Battelli MG, Polito L, Bortolotti M, Bolognesi A. Xanthine oxidoreductase in cancer: more than a differentiation marker. Cancer Med. 2016;5:546-57.

36. Linder N, Bützow R, Lassus H, Lundin M, Lundin J. Decreased xanthine oxidoreductase (XOR) is associated with a worse prognosis in patients with serous ovarian carcinoma. Gynecol Oncol. 2012;124:311-8.

37. Wang Y, Cui Q, Wang C, Liu S, Du R, et al (2020) C1QBP regulates apoptosis of renal cell carcinoma via modulating xanthine dehydrogenase $(X D H)$ mediated ROS generation.

38. Yuan C, Xu X-H, Wang X-L, Xu L, Chen Z, Li Y-Q. (2016) Relationship between serum uric acid and metastatic and nonmetastatic rectal cancer patients with undergoing no chemotherapy. Medicine 95.

39. Dhankhar R, Dahiya K, Sharma TK, Ghalaut VS, Atri R, Kaushal V. Diagnostic significance of adenosine deaminase, uric acid and C-reactive protein levels in patients of head and neck carcinoma. Clin Lab. 2011;57:795-8.

40. Fini MA, Elias A, Johnson RJ, Wright RM. Contribution of uric acid to cancer risk, recurrence, and mortality. Clin translational Med. 2012;1:1-15.

41. Shi L, Chen S, Yang L, Li Y. The role of PD-1 and PD-L1 in T-cell immune suppression in patients with hematological malignancies. J Hematol Oncol. 2013;6:1-6.

42. Dziaman T, Banaszkiewicz Z, Roszkowski K, Gackowski D, Wisniewska E, et al. 8-0xo-7, 8dihydroguanine and uric acid as efficient predictors of survival in colon cancer patients. Int $\mathrm{J}$ Cancer. 2014;134:376-83.

43. Pastor-Anglada M, Pérez-Torras S. Emerging roles of nucleoside transporters. Front Pharmacol. 2018;9:606. doi:10.3389/fphar.2018.00606.

44. Senyavina N, Tonevitskaya S. Effect of hypoxanthine on functional activity of nucleoside transporters ENT1 and ENT2 in caco-2 polar epithelial intestinal cells. Bull Exp Biol Med. 2015;160:160-4. doi:10.1007/s10517-015-3118-z.

45. Kim K, Yeo S-G, Yoo BC. Identification of hypoxanthine and phosphoenolpyruvic Acid as serum markers of chemoradiotherapy response in locally advanced rectal cancer. Cancer Res treatment: official J Korean Cancer Association. 2015;47:78.

\section{Figures}



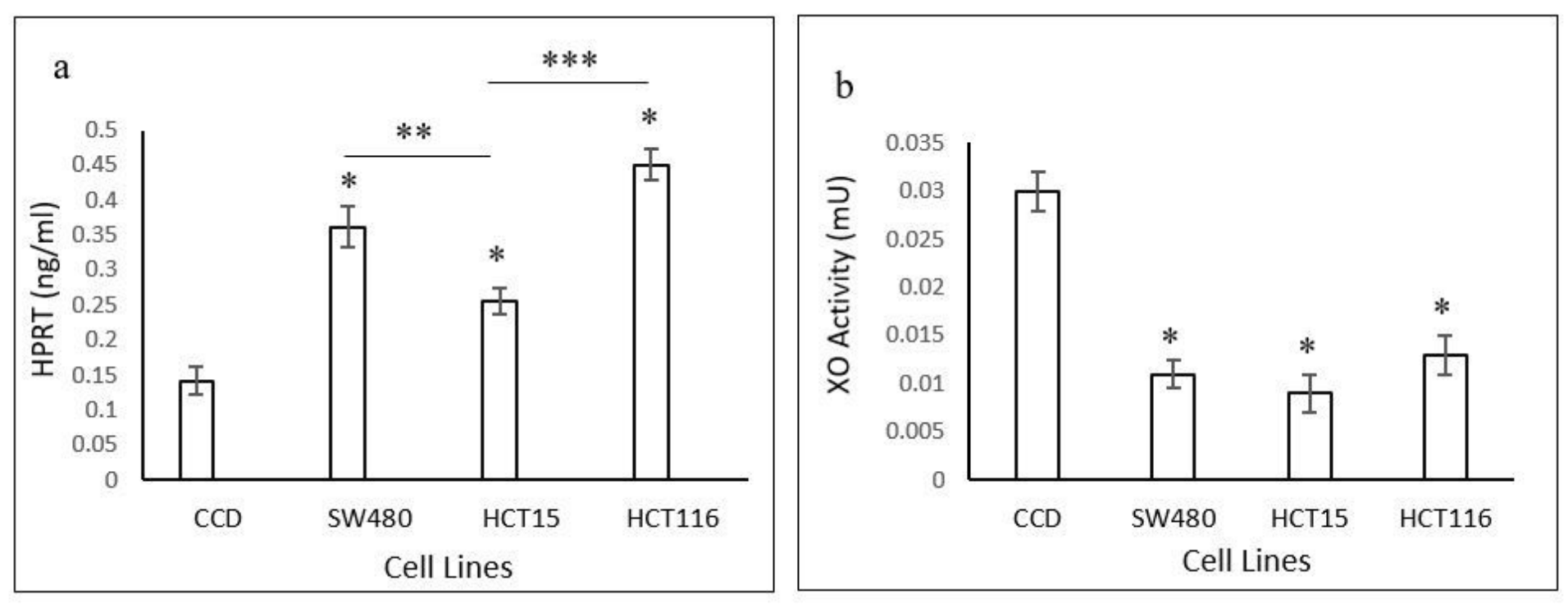

\section{Figure 1}

Enzymes levels in normal colon epithelial cell lines (CCD-841CoN) and CRC cell lines SW480 (Dukes' B), HCT15 (Dukes' C) and HCT116 (Dukes' D). a shows HPRT level, b shows the XO activity. Data is presented as means \pm SD $(n=9)$. * indicates significant difference between normal vs CRC cell lines, $p \leq$ 0.05 . ${ }^{\star \star}$ indicates significant difference between stage $B$ vs stage $C, p \leq 0.05$, $* \star \star$ indicates significant difference between stage $C$ vs stage $D, p \leq 0.05$.
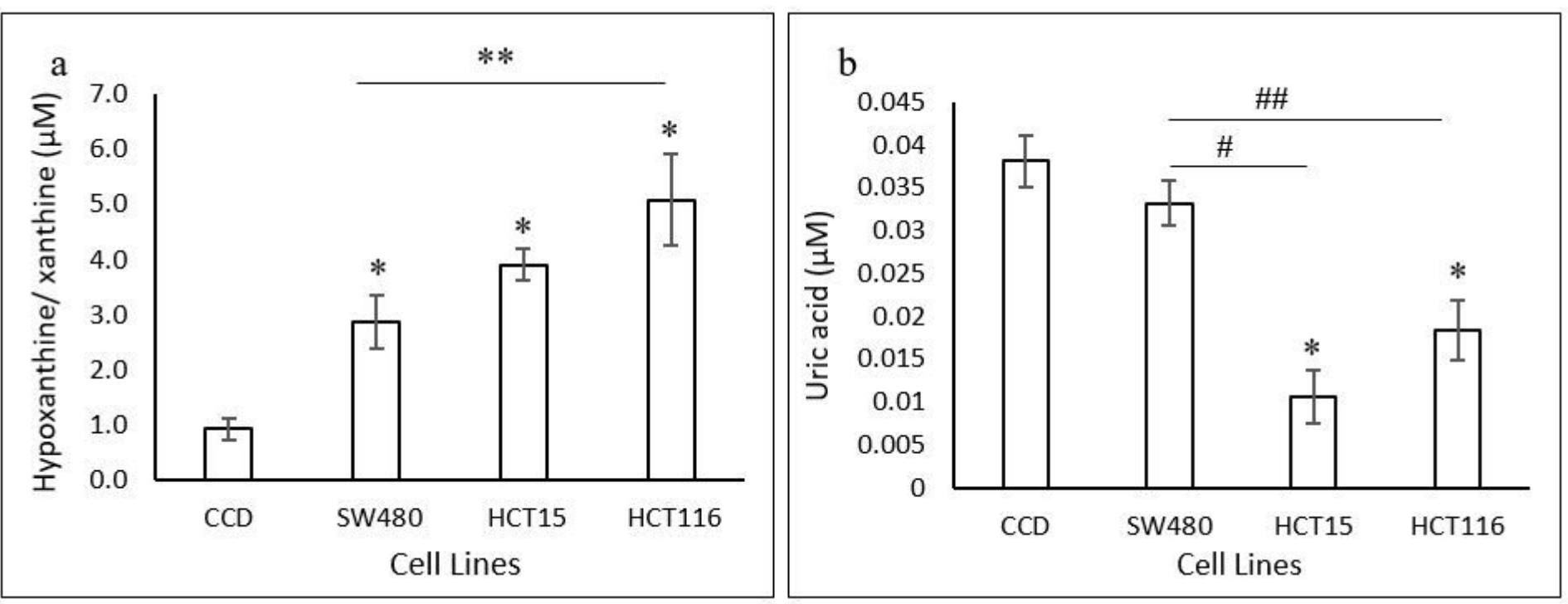

Figure 2

Metabolites levels in normal colon epithelial cell lines (CCD-841CoN) and CRC cell lines SW480 (Dukes' B), HCT15 (Dukes' C) and HCT116 (Dukes' D). a hypoxanthine/xanthine level. b UA level. Data is presented as means \pm SD $(n=9)$. * indicates significant difference between normal vs CRC cell lines, $p \leq$ 0.05 , ** indicates significant difference between stage $B$ vs stage $D, p \leq 0.05$. \# indicates significant 
difference between stage $B$ vs stage $C, p \leq 0.05$, \#\# indicates significant difference between stage $B$ vs stage $D, p \leq 0.05$.

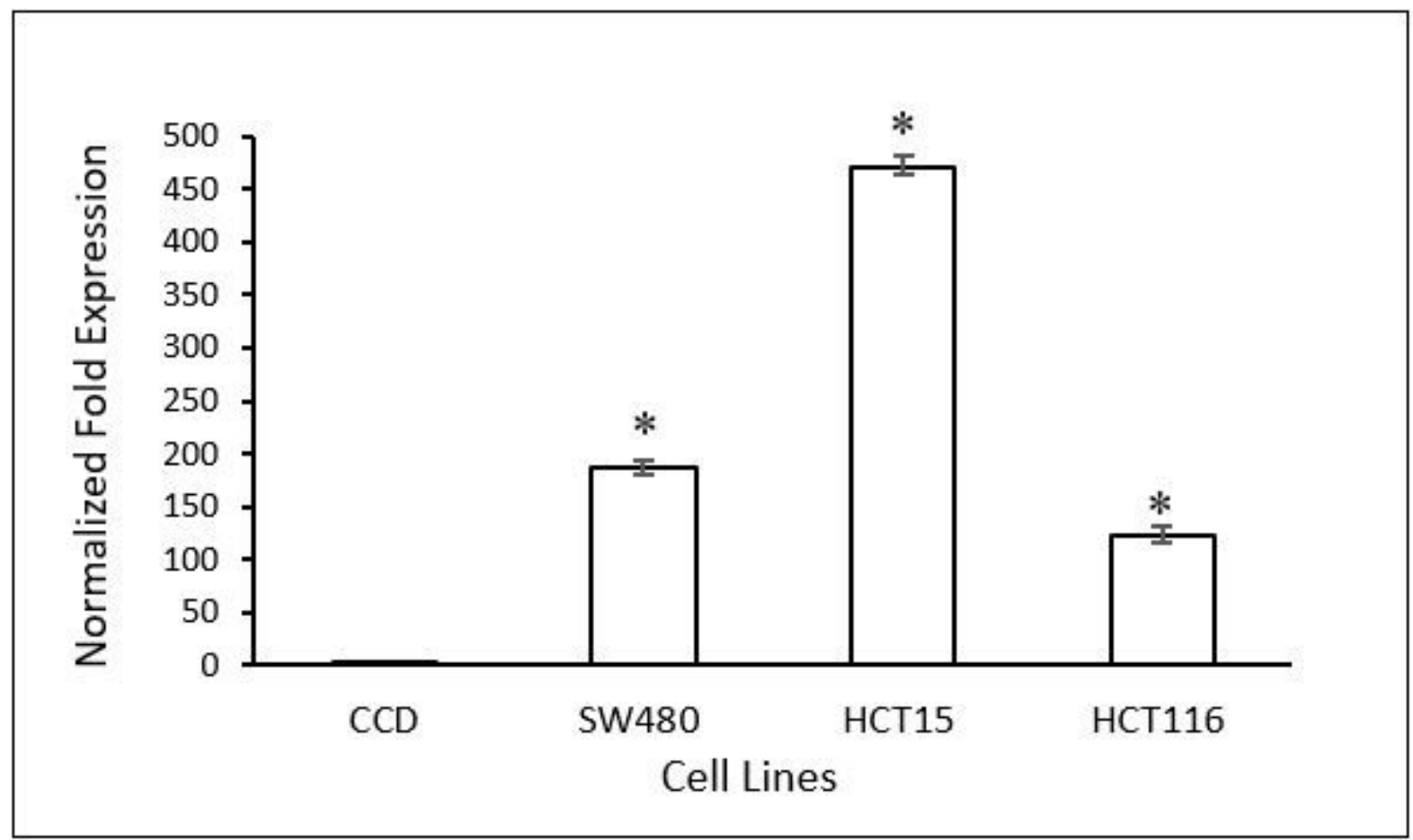

Figure 3

Differential expression of ENT2 gene in normal colon epithelial cell lines (CCD-841CoN) and CRC cell lines SW480 (Dukes' B), HCT15 (Dukes' C) and HCT116 (Dukes' D). Data is presented as means \pm SD $(n=9)$. * indicates significant difference between normal vs CRC cell lines, $p \leq 0.05$.

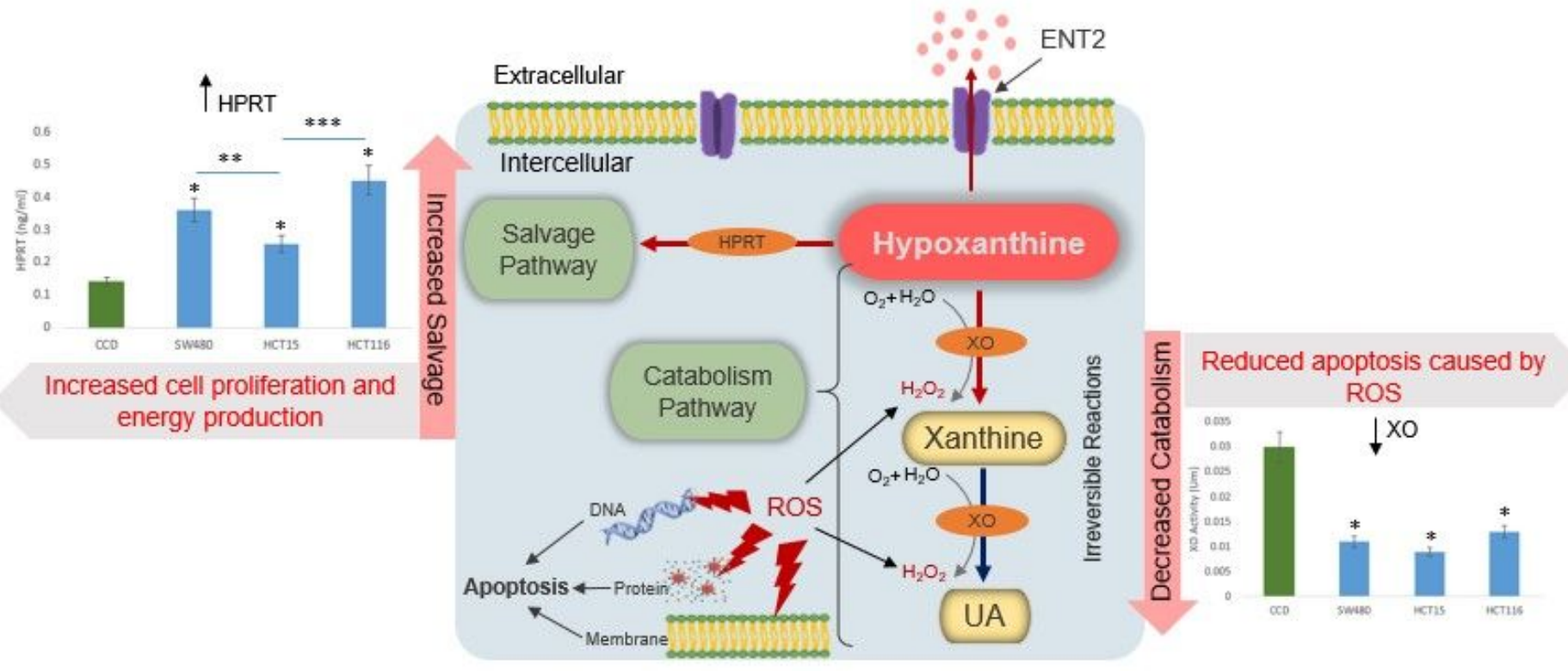




\section{Figure 4}

Schematic diagram of purine salvage and catabolism pathways in CRC cells. CRC cells resorted to modify the purine metabolism by two ways; first by increasing the rate of salvage pathway in order to meet the demand of rapid cell proliferation by generating new nucleotides for DNA synthesis via hypoxanthine recycling. Second by decreasing the rate of catabolism pathway in order to avoid the detrimental effects of ROS. 